\title{
Author Correction: Interfacial photochemistry at the ocean surface is a global source of organic vapors and aerosols
}

\author{
Martin Brüggemann (D) ${ }^{1,2}$, Nathalie Hayeck (i) ${ }^{1} \&$ Christian George (iD) ${ }^{1}$ \\ Correction to: Nature Communications https://doi.org/10.1038/s41467-018-04528-7; published online 23 April 2018
}

The authors became aware of a mistake in the data displayed in the original version of the paper. Specifically, for the calculation of the total emission estimates (i.e., from an average molecular weight and summed laboratory production values for all VOCs), the authors mistakenly added seasonal estimates to the annual estimates because both values are stored in the same variable of the code. Eventually, this additional sum resulted in a doubling of emission estimates.

As a result of this, the following changes have been made to the originally published version of this Article:

The fifth sentence of the abstract originally read "Our results indicate global emissions of 46.4-184 Tg C yr ${ }^{-1}$ of organic vapors from the oceans into the marine atmosphere and a potential contribution to organic aerosol mass of more than $60 \%$ over the remote ocean."

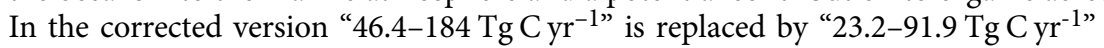

The seventh sentence of the second paragraph of the Introduction originally read "We infer global emissions of $65.0-257$ Tg $\mathrm{yr}^{-1}$

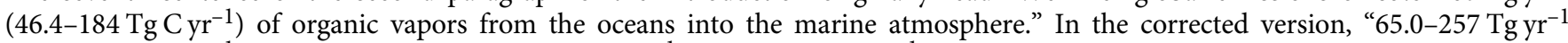

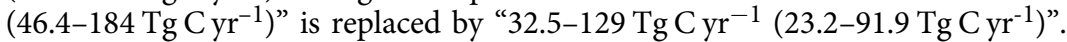

The last sentence of the first paragraph of the Results subheading "Marine isoprene emissions from interfacial photochemistry" originally read "In the same way, we infer total emissions of organic vapors from abiotic interfacial photochemistry in the range of 65.0-257 $\mathrm{Tg} \mathrm{yr}^{-1}\left(46.4-184 \mathrm{Tg} \mathrm{C} \mathrm{yr}^{-1}\right)$, hence, contributing significantly to marine VOC emissions." In the corrected version, “65.0-257 $\mathrm{Tg} \mathrm{yr}^{-1}\left(46.4-184 \mathrm{Tg} \mathrm{C} \mathrm{yr}^{-1}\right)$ ” is replaced by “32.5-129 $\mathrm{Tg} \mathrm{C} \mathrm{yr}^{-1}$ (23.2-91.9 $\left.\mathrm{Tg} \mathrm{C} \mathrm{yr}^{-1}\right)$ ”.

This has been corrected in both the PDF and the HTML versions of the Article. While the new estimates are lower than previously reported this error does not affect the original discussion or conclusions of the Article. The authors apologize for the confusion caused by this mistake.

Published online: 08 August 2018

Open Access This article is licensed under a Creative Commons Attribution 4.0 International License, which permits use, sharing, adaptation, distribution and reproduction in any medium or format, as long as you give appropriate credit to the original author(s) and the source, provide a link to the Creative Commons license, and indicate if changes were made. The images or other third party material in this article are included in the article's Creative Commons license, unless indicated otherwise in a credit line to the material. If material is not included in the article's Creative Commons license and your intended use is not permitted by statutory regulation or exceeds the permitted use, you will need to obtain permission directly from the copyright holder. To view a copy of this license, visit http://creativecommons.org/licenses/by/4.0/.

(C) The Author(s) 2018

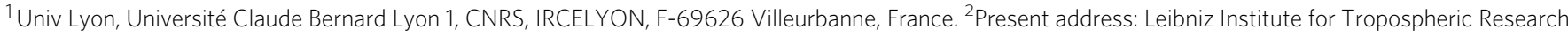
(TROPOS), Permoserstr. 15, 04318 Leipzig, Germany. Correspondence and requests for materials should be addressed to 